\title{
Editorial
}

\section{Livestock production evolving to contribute to sustainable societies}

\author{
M. Gill ${ }^{1 \dagger}$, J. P. Gibson ${ }^{2}$ and M. R. F. Lee ${ }^{3}$ \\ ${ }^{1}$ School of Biological Sciences, University of Aberdeen, AB24, 2TZ; ${ }^{2}$ School of Environmental and Rural Science, University of New England Armidale, NSW 2350 \\ Australia; ${ }^{3}$ Rothamsted Research, North Wyke, Okehampton, Devon, EX20 2SB and University of Bristol, Langford, Somerset, BS40 5DU
}

There is a hypothesis in the anthropological literature (e.g. Milton, 2003) that our complex human brains would not have developed without hominoids having routine access to foods of animal origin. In many countries, therefore, the consumption of animal source foods, and meat in particular, became part of a cultural identity, while in others (e.g. India) vegetarianism has long been part of the cultural/religious identity (approx. 30\% of Indians are vegetarian, although the majority of those consume milk products). In the twenty first century, humans can, theoretically, have access to nonanimal-derived sources of nutrients required for brain development, so animal products are no longer as important for nutrition as they were for our ancestors. There are also other issues, however, associated with livestock production which impact on the consumption of animal products. Culture in many countries has evolved to give a higher priority to the welfare of farm animals and there are additional ethical issues associated with the negative environmental impacts of livestock production. We read a lot, therefore, about the rise of veganism, with calls for diets free of animal products, yet there is also evidence that the consumption of meat at a country level increases as the income of that country increases (FAO, 2009). The average global per capita meat consumption at over $40 \mathrm{~kg}$, has, therefore, doubled from the consumption in 1960. However, the annual global rate of increase in both meat and milk consumption is projected (OECD/FAO, 2017) to decrease slightly in the decade from 2017-2026, to $1.5 \%$ per annum for meat and $1.9 \%$ per annum for milk.

The choice of whether to eat animal products or not is therefore a complex one, if an individual, or society, wants to think of the consequences for human health and well-being, the environment and global economics (the three pillars of sustainable societies). Do we have robust evidence to support those choices - we would argue we

\footnotetext{
${ }^{\dagger}$ E-mail: m.gill@abdn.ac.uk
}

don't - but we do know that livestock production systems need to evolve to meet some major concerns of $21^{\text {st }}$ century societies and we believe that research can help guide that evolution.

This special issue is an output of the 2016 conference on 'Steps to Sustainable Livestock' in Bristol, UK organised by the Global Farm Platform Initiative (www.globalfarmplatform. org; GFP) in response to their positioning paper of the same name published in Nature (Eisler et al., 2014). The GFP represents a unique resource that can assist with the urgent need to assess the role of ruminant livestock in meeting our requirements for food and abating their environmental impact in the broader context of contrasting agricultural systems across a wide range of climates and ecosystems.

The GFP now comprises 15 model farms in 11 countries representing various latitudes and biomes. Each of these individual facilities is distinct, having its own attributes and focus on research topics of particular relevance to its surrounding region and ruminant farming systems. Nevertheless, the model farms are all united by the common overall mission, vision and plan of the GFP. Of particular importance is the common interdisciplinary research strategy which promotes the use of standardised methodologies wherever feasible to ensure that results are directly comparable across regions and that the value of the combined research output is correspondingly greater than the sum of the parts. This is being achieved through dialogue, workshops, staff and student exchanges and collaborative funding applications which have been brought about by the creation of the GFP.

Seven papers cannot address all the ways by which current livestock production systems could be enhanced in ways to contribute more positively to social, environmental and economic societal issues. Yet they illustrate that there are benefits as well as disbenefits of livestock production in terms of the sustainability of today's societies. Societal concerns have changed (and are changing) as countries have 
become wealthier but often the expression of those concerns ignores the historical rationale behind the human consumption of animal products. As discussed in the papers, the trade-offs are complex, and data in some areas is more detailed than in others. Livestock are one part of broader agricultural systems that depend on land and it was not the intention of the original workshop to consider livestock relative to alternative agricultural systems. Overall the intention was to contribute evidence to help underpin those making choices about diet as well as evidence for those involved directly in the evolution of livestock systems more closely aligned with the priorities of today's societies.

The series of papers starts with one by Perry and colleagues which explores the role of animal health in sustainability of livestock systems. The paper highlights a previously proposed concept for prioritising, identifying and delivering health interventions based on a classification of livestock disease in relation to human impact, of "hot spots", "cold spots" and "the worried well". The "worried well" being mostly in developed countries where animal health problems are, by global standards, relatively low and impacts on human health relatively small but degree of worry and consequent focus is very high. The shift needs to be to the hot spots of livestock disease that have also high impact on human health. The authors propose that, given the large proportion of human disease that originates from or is linked to livestock, the concept of "One-health", the joint management of human and livestock health, should become a fourth pillar of sustainability, in addition to economics, society and environment. They illustrate with three case studies how sustainability issues interface with the management and improvement of animal health.

This concept of linking livestock with human health is also a theme in the paper by Givens, which explores the changing nature of nutrient requirements as we age and hence how achieving a healthy diet may be made easier at some lifestages through the consumption of meat and milk. Givens challenges some of the analysis of evidence for the negative health impacts of consumption of meat and milk, pointing out the role of meat processing - which may have been essential in the past for ensuring food safety, but as we live longer can increase the incidence of diseases more associated with old age, such as cancer. Givens also highlights evidence from today's teenagers of how avoidance of animal products may have led to decreases in the intake of key minerals, which could have an influence on health status in later life. He also emphasises the health risks associated with obesity.

The paper by Broderick is the first of two papers which recognise the importance of ruminants (mainly cattle and sheep) in turning plant material which cannot be digested by humans, into high quality food for humans. The downside of relying solely on such diets is a lower productivity and consequently higher greenhouse gas emissions. Broderick argues that more targeted feeding strategies could mitigate some of this increase, particularly by paying more attention to matching the level of protein in the diet with the requirements of cows at different stages of lactation. He also makes the case for the use of smaller breeds and for aiming to maximise the yield of milk components rather than milk yield, citing evidence from the USA where the consumption of products made from milk (e.g. cheese) is growing at the expense of consumption of fluid milk.

Wilkinson and Lee also emphasise the contribution of ruminants in producing high quality human food from human-inedible feeds including grass and by-products from other sectors of the food and drinks industry (e.g. distillers' grains). Using documented assumptions, they estimate the area of land required (separated into arable and grassland) by a range of northern-European livestock systems and illustrate that apart from cereal-beef systems, ruminant systems require considerably less arable land than monogastric systems of pig and poultry production. They recommend the restriction of use of human-edible feeds, and preferential use of by-products to higher-producing livestock and advocate the optimisation of forage resources in the diets of all ruminant species.

Makkar continues the theme of feeding systems for livestock which would decrease the use of arable land for production of feed. He illustrates (as did Broderick) the benefits of feeding strategies matched more closely with requirements and refers to work from East Asia on the safe recycling of food waste into animal feeds. He provides data on the composition of various insect meals, drawing attention to some of the deficiencies in amino acid composition, important when incorporating such meals into the diets of monogastrics. Makkar also makes the important point about the need to consider the negative impacts of livestock production on the environment beyond simply greenhouse gas emissions, referring to water use and disruption of the nitrogen cycle.

The final two papers describe methods for exploring trade-offs between different ways of minimising negative environmental impacts. The first by Van Kernebeek uses a mathematical model to explore ways of enhancing phosphorus recycling. The model was parameterised using data from the Netherlands, which are assumed to be typical of north-western European conditions. Recycling of human waste was identified as being particularly important in restricting phosphorus loss from food systems. When this is in place, then a small amount of animal protein in the human diet results in the most sustainable use of phosphorus.

The final paper by Takahashi and colleagues describes the use of an intensively instrumented farm-scale ruminant research facility (a member of the GFP) located in southwest UK, to explore trade-offs between economic and environmental benefits and disbenefits of different management strategies. They refer to the complexity of unravelling these trade-offs on commercial farms and highlight the potential of platforms which can make measurements at a whole farm-scale. There is a particular focus on which are the best metrics to use as surrogates for environmental "health", 


\section{Gill, Gibson and Lee}

with an emphasis on those relating to soil "health" and biodiversity.

These seven papers illustrate that much is known that can guide decision making today but they also illustrate that the diversity and complexity of the impacts of livestock production should not be looked at in isolation but as part of agriculture more broadly if food production is going to respond appropriately to the altered economic and social drivers of twenty first century consumers.

\section{References}

Eisler MC, Lee MRF, Tarlton JF, Martin GB, Beddington J, Dungait JAJ, Greathead H, Liu J, Mathew S, Miller H, Misselbrook T, Murray P, Vinod VK, Van Saun R and Winter M 2014. Steps to sustainable livestock. Nature 507, 32-34. FAO 2009. The State of Food and Agriculture:livestock in the balance. FAO, Rome. pp 166.

Milton K 2003. The Critical Role Played by Animal Source Foods in Human (Homo) Evolution. The Journal of Nutrition 133, 3886S-3892S.

OECD/FAO 2017. OECD/FAO Agricultural Outlook 2017-2026. http://www.fao org/publications/oecd-fao-agricultural-outlook/2017-2026/en/ 